\title{
Os itinerários formativos da educação secundária nos contextos sueco e espanhol e a educação profissionalizante
}

\section{The formative itineraries of secondary education in the swedish and spanish contexts and professionalizing education}

\section{Los itinerarios formativos de la educación secundaria en los contextos suecos y españoles y la educación profesional}

RESUMO: Este artigo analisa as opções de Educação Profissional de nível médio que os sistemas de educação básica da Suécia e da Espanha oferecem para os seus jovens para, ao final, tecer algumas considerações comparativas com a realidade da Educação Profissional de nível médio existente no Brasil. Consideramos relevante comparar esses dois sistemas de Educação Profissional de nível médio, pois o exercício da comparação nos mostra as principais semelhanças e diferenças entre tais sistemas e a realidade educacional brasileira no que se refere à Educação Profissional de nível médio. A metodologia adotada foi baseada nos estudos e conceitos provenientes da área da Educação Comparada e Internacional.

Palavras-chave: Educação Profissional. Educação comparada. Políticas educacionais.

ABSTRACT: This article proposes to analyze the options of Professional Education of secondary level that the basic education systems of Sweden and Spain offer for its young people to, in the end, make some comparative considerations with the reality of the Professional Education of secondary level existing in Brazil. We consider it relevant to compare these two medium level Professional Education systems, because the exercise of the comparison shows us the main similarities and differences between such systems and the Brazilian educational reality with regard to medium level Professional Education. The methodology adopted was based on studies and concepts from the area of Comparative and International Education. Keywords: Professional Education. Comparative education; Educational policies.

\footnotetext{
${ }^{1}$ Universidade Estadual Paulista (UNESP). Campus de Assis. E-mail: carlos.brandao@unesp.br
} 
RESUMEN: Este artículo propone analizar las opciones de Educación Vocacional de nivel secundario que los sistemas de educación básica de Suecia y España ofrecen a sus jóvenes para, al final, hacer algunas consideraciones comparativas con la realidad de la Educación Vocacional de nivel secundario existente en el Brasil. Consideramos relevante comparar estos dos sistemas de Educación Profesional de nivel medio, ya que el ejercicio de la comparación muestra a nosotros las principales similitudes y diferencias entre tales sistemas y la realidad educativa brasileña con respecto a la Educación Profesional de nivel medio. La metodología adoptada se basó en estudios y conceptos del área de Educación Comparada e Internacional. Palabras clave: Educación profesional. Educación comparada; Políticas educativas. 


\section{INTRODUÇÃO}

A comparação entre sistemas educacionais não é atualmente o tópico mais discutido na Educação Comparada. Segundo Cook, Hite e Epstein (2004), o tema atual mais proeminente no campo da Educação Comparada é a "marca da globalização". Ainda assim, neste artigo, nos propomos a analisar as opções de Educação Profissional de nível médio que os sistemas de educação básica da Suécia e da Espanha oferecem para os seus jovens.

Iniciamos por uma descrição dos contextos educacionais da Suécia e da Espanha, procurando mostrar os caminhos educacionais possíveis na oferta e no atendimento dos jovens desses países, quando optam pela Educação Profissional de nível médio, seguindo para o respectivo mercado de trabalho ou, por vezes, optando por seguir em direção ao ensino superior. Consideramos relevante comparar esses dois sistemas de Educação Profissional de nível médio, apesar das significativas diferenças entre os dois países (cultura, história, tamanho, densidade populacional, etc), pois o exercício da comparação tem o objetivo de nos mostrar as principais semelhanças e diferenças entre tais sistemas e a realidade educacional brasileira no que se refere à Educação Profissional de nível médio. Por outro lado, é muito provável que a estrutura e o funcionamento da Educação Profissional, tanto na Suécia como na Espanha, sejam realidades educacionais pouco conhecidas de nós brasileiros (especialmente a realidade educacional sueca).
Nosso principal objetivo é destacar as principais semelhanças e diferenças entre as opções de oferta de Educação Profissional presentes nos sistemas educativos da Suécia e da Espanha, no sentido dos itinerários formativos profissionais de nível médio nesses países. Nosso principal referencial teóricometodológico são os estudos comparativos na área educacional, com a utilização de revisão da literatura. $\mathrm{Na}$ conclusão, teceremos algumas considerações comparativas com a realidade da Educação Profissional de nível médio existente no Brasil.

De acordo com Broadfoot, a educação comparada "sempre foi explícita ou implicitamente reformadora" (Broadfoot, 2000, p. 366). Uma outra tendência tradicional nos estudos de Educação Comparada é a ideia de que ela pode "tomar emprestado" ou "emprestar" um modelo educacional para outro (Phillips \& Ochs, 2003; Steiner-Khamsi, 2004). Assim, de início, há que se ressaltar que o presente artigo não pretende propor nenhuma reforma para a Educação Profissional de nível médio no Brasil e, nem mesmo, "tomar emprestado" modelos estrangeiros para aplicação na realidade educacional brasileira.

No campo da Educação Comparada há um consenso acadêmico de que a sua inauguração se dá com a obra do francês Marc-Antonie Jullien, intitulada "Esquisse et vues préliminaires d'un ouvrage sur l'éducation comparée", em meados do 
século XIX, mais exatamente em 1817, no contexto do chamado período póslluminismo (Kaloyiannaki \& Kazamias, 2012)². De lá para cá, alguns autores traçaram "linhas do tempo" com as diversas fases (ou períodos) da Educação Comparada (Bray et al., 2015), alguns outros autores que afirmam que não há uma Educação Comparada, mas sim, "múltiplas educações comparadas" (Cowen, 2000, p. 333), além de outros que chegam a propor uma Educação Neocomparada (Broadfoot, 2012).

Mas, tentando simplificar sem diminuir, qual seria o objetivo central da Educação Comparada? Para Franco, e em poucas palavras, seria o conhecer o "outro", no sentido de tudo aquilo (sistemas, propostas, políticas, métodos, projetos, etc) que, ao conhecermos, nos ajuda a aprofundar o conhecimento que temos de nós mesmos e dos outros. Assim, se quisermos, podemos aplicar (ou não), os novos conhecimentos para melhorar aquilo que fazemos, cada qual dentro dos seus respectivos contextos, sempre levando-se em consideração a história, a cultura, a política, etc, de cada um dos referidos contextos. Nesse sentido, o processo de comparação passa a ser "um processo de perceber diferenças e semelhanças" (Franco, 1992, p. 14).

Nas primeiras décadas do século $\mathrm{XX}$, Kandel foi um dos primeiros autores no campo da Educação Comparada a olhar para esse campo de estudo como uma metodologia adequada para a comparação dos sistemas de ensino entre os países que já os possuíam. Para Kandel, para entender os sistemas nacionais de educação, "as forças políticas, sociais e culturais devem ser levadas em conta", bem como o "caráter nacional” que determina suas particularidades (Kandel, 1933, p. 27). Precursor de Kandel, Sadler já afirmava, em 1900, que ao

(...) estudar sistemas educacionais estrangeiros, não devemos esquecer que o que ocorre fora das escolas é ainda mais importante do que aquilo que ocorre dentro delas, e as coisas externas governam e interpretam as coisas internas. Não podemos passear pelos sistemas educacionais do mundo, como uma criança em um jardim, colhendo uma flor aqui e umas folhas acolá, e então esperar que, se fincarmos na terra o que colhemos, teremos uma planta viva. Um sistema nacional de educação é uma coisa viva, o resultado de lutas e dificuldades já esquecidas e 'de batalhas do passado'. Traz dentro de si algo do funcionamento secreto da vida nacional. Ao mesmo tempo em que busca remediálas, reflete as falhas do caráter nacional. (Sadler, 1900, p. 310).

Os dois autores acima citados expressam o que podemos chamar de dois pontos chaves nos estudos que possuem a Educação Comparada como metodologia de pesquisa, quer sejam, a análise de sistemas nacionais de ensino e a contextualização das realidades educacionais. Sem uma boa contextualização, não há (para esses e

\footnotetext{
${ }^{2}$ Kaloyiannaki e Kazamias consideram também que o campo da Educação Comparada inaugurou-se com "os discursos de formuladores de políticas educacionais, reformadores e administradores na área da educação na Europa e nos Estados Unidos, como Horace Mann, Calvin Stowe e Henry Barnard, nos Estados Unidos; Victor Cousin, na França; e o poeta e inspetor escolar Matthew Arnold, na Inglaterra." (Kaloyiannaki \& Kazamias, 2012, p. 25).
} 
muitos outros autores), uma adequada análise dos próprios sistemas de ensino a serem analisados ${ }^{3}$.

Levando-se em conta, por um lado, as realidades locais (nacionais) e, por outro lado, o processo incisivo de globalização, especialmente econômico e cultural, presente no início do século XXI, quais seriam os desafios atuais para um estudo que utiliza a metodologia da educação comparada para realizar uma pesquisa no campo da Educação Profissional de nível médio?

As respostas a essa pergunta, embora pontualmente diferentes, podem convergir para uma mesma direção. Segundo Carvalho, o "processo de reorganização dos sistemas educacionais em diferentes países, segundo padrões sem fronteiras" é o que dá "uma nova importância à Educação Comparada e coloca seus pesquisadores diante de novos desafios" (Carvalho, 2014, p. 135). Já para Lima e Afonso, o contexto atual exige que 0 pesquisador seja capaz de "identificar temas recorrentes, semelhanças na retórica produzida e propor soluções, mas também dissimilaridades e particularidades nacionais" e, ao mesmo tempo, evitar a excessiva valorização dos fatores locais. Assim, segundo esses autores 0 pesquisador em Educação Comparada deve identificar o que é comum ou idêntico e, simultaneamente, o que é único e específico (Lima \& Afonso, 2002).

No caso específico de nossa pesquisa, que visa comparar a maneira como está disposta, em termos de organização e caminhos (oportunidades), a Educação Profissional de nível médio, nos sistemas de ensino de dois países europeus (Suécia e Espanha) com a realidade da Educação Profissional de nível médio de um país da América do Sul (Brasil), partimos da realidade de que estaremos comparando os sistemas educacionais de dois países considerados desenvolvidos

e pertencentes ao chamado "Primeiro Mundo" com o sistema educacional de um país considerado "em desenvolvimento", pertencente ao chamado "Terceiro Mundo". Para procedermos corretamente na análise desse gap existente entre as realidades educacionais de países europeus com a realidade educacional brasileira, nos apoiamos em Franco, que afirma que,

[...] a questão dos estudos comparativos e da educação dos países dependentes, comparados aos sistemas educacionais dos países avançados, é fundamentalmente a análise do produto de uma situação assimétrica de dominação / dependência, que se qualifica para 0 desenvolvimento desigual e combinado dos países sob a estratégia da expansão da acumulação de capital transnacional (Franco, 1992, p. 33).

Assim, seguindo o raciocínio dessa autora, o primeiro ponto que merece toda nossa atenção é ver (e entender) a "distância dramática que nos separa e separa nossos países e nossa educação dos países economicamente desenvolvidos". segundo ponto é entender que em certo

\footnotetext{
${ }^{3}$ No Brasil, um dos primeiros autores a utilizar a metodologia da Educação Comparada, já em 1961, como ferramenta adequada para a análise dos sistemas de ensino internacionais e as suas respectivas comparações foi Lourenço Filho (2004). Naquele momento, a década de 60 do século passado, King considerava que, para ser acadêmica e cientificamente reconhecida, a Educação Comparada precisava ser entendida como uma ciência social (King, 1965, p. 159).
} 
sentido, seja quantos forem os sistemas de ensino a serem comparados, em certa medida eles são "incomparáveis, na medida em que são frutos de processos históricos particulares, de trajetórias singulares, apesar de suas semelhanças", mas, por outro lado, e seguindo, por exemplo, os ensinamentos de Sadler,
Kandel e Lourenço Filho, a Educação Comparada serve para isso mesmo, ou seja, comparar sistemas de ensino localizados em contextos diferentes e, entre outras coisas "frutos de processos históricos particulares" e "de trajetórias singulares" (Franco, 1992, p. 34-35).

\section{As opções de ensino médio e profissionalizante na Suécia}

A estrutura do sistema de Educação Básica da Suécia é consideravelmente semelhante à estrutura do sistema de Educação Básica brasileiro, com algumas poucas diferenças. Todo o sistema educacional sueco é regido pela Lei Educacional de 2010 (Skollagen), a qual é complementada pelo Läroplän (currículo) e pelo Kursplan (planos de curso), ao passo que questões educacionais específicas são reguladas por instruções específicas (förordningen). A fiscalização do sistema educacional sueco é feita pela Agência Nacional Sueca de Educação (Skolverket) e a supervisão da qualidade da educação sueca, tanto pública como privada (também chamada de independente), é feita por outra agência chamada Skolinspektionem (Inspeção Escolar Sueca).

Como o nível de ensino que nos interessa é a Educação Profissional de nível médio, começaremos, neste tópico, pelo nível secundário da organização educacional sueca. A escola secundária sueca não é obrigatória e possui duração de três anos. Embora não seja obrigatório, o ensino secundário (gymnasiet) na Suécia é frequentado pela grande maioria dos jovens suecos, que se chama Educação Secundária Superior. O ensino secundário sueco (gymnasieskola), assim como outros níveis de educação, é gratuito ${ }^{4}$.

Para entrar no gymnasiet (Ensino Secundário) o aluno, com base nas notas obtidas no nono ano do Ensino Básico (último ano do terceiro ciclo, högstadiet), inscreve-se na escola de sua preferência. Este ensino secundário é oferecido em dois tipos de escola, as escolas regulares (gymnasieskola) e as escolas para alunos com dificuldades de aprendizagem (gymnasiesärskola), tanto livres como não obrigatórias.

As principais funções do ensino secundário sueco (gymnasiet) são proporcionar aos jovens suecos uma base de conhecimentos para os auxiliar na sua escolha profissional (ensino superior) e para complementar os conhecimentos adquiridos no ensino básico obrigatório (grundskola), contribuindo para o seu desenvolvimento pessoal e para a sua participação ativa na vida social (construção da cidadania). $O$ ensino secundário sueco é destinado a jovens

\footnotetext{
${ }^{4}$ Há também um pequeno número de escolas internacionais para filhos de cidadãos estrangeiros cuja permanência na Suécia é temporária, as quais recebem financiamento parcial do governo (Wikander, 2010).
} 
entre os 16 e os 20 anos. Depois dos 20 anos, o jovem é considerado adulto e pode frequentar o ensino secundário de adultos ou o ensino especial para adultos com dificuldades de aprendizagem (särvux).

O ensino secundário sueco (gymnasieskola) é composto por três tipos de cursos (ou programas): programas nacionais, programas introdutórios e programas que diferem da estrutura do programa nacional, como programas para 0 desenvolvimento de atividades esportivas. Os alunos que, no final do nono ano do ensino básico obrigatório, tiverem sido aprovados na língua sueca, inglês e matemática e tiverem passado em outras 9 disciplinas, têm o direito de aderir a um programa preparatório da faculdade. Os programas nacionais abrangem 18 programas de estudo diferentes, 12 dos quais são direcionados para a formação profissional e 6 desses programas nacionais são projetados para preparar os alunos para o ensino superior. Esses programas nacionais consistem em disciplinas, orientações, especializações e um tipo de projeto de conclusão (projeto de diploma).

Para além dos chamados Programas Nacionais, o sistema educativo sueco oferece ainda outros 5 programas, chamados "programas introdutórios" para alunos que não são elegíveis para um programa nacional, ou seja, alunos que, no final da escolaridade obrigatória (mais especificamente no $9^{\circ}$ ano da grundskola), embora aprovados, não obtiveram pontuação suficiente para ingressar em um Programa Nacional.
Nenhum desses cinco programas introdutórios fornece um diploma do ensino médio porque seu objetivo é preparar o aluno para participar de um Programa Nacional ou preparar o aluno para entrar no mercado de trabalho, embora com uma preparação mais básica, abaixo do nível de profissionalismo dos programas nacionais de formação profissional. A oferta destes programas é da responsabilidade dos municípios que, por sua vez, são obrigados a ter lugares para todos os jovens que desejam frequentar, dentro dos critérios estabelecidos, o ensino secundário sueco.

Finalmente, no contexto da estrutura educacional sueca, existem Folk High Schools (folkhögskola). Estas escolas destinam-se a jovens com mais de 18 anos e a sua principal característica distintiva é o facto de disporem de uma organização curricular extremamente flexível e de uma proposta pedagógica baseada na ideia da educação popular.

A concepção central das Folk High Schools (folkhögskola) é o reconhecimento e a valorização da liberdade ideológica de ensinar e de aprender como pilares da democracia, além de salvaguardar os valores culturais básicos da humanidade, fortemente influenciados pela tradição iluminista. Assim, a missão dessas escolas é defender a democracia e lutar pelos direitos das minorias, com a discussão e o diálogo como ferramentas pedagógicas para a construção da cidadania e de uma sociedade mais justa.

Todas as Folk High Schools (folkhögskola) oferecem o curso geral (Allmän kurs ou Behörighetsgivande kurs) cujo objetivo é conceder escolaridade primária obrigatória 
(grundskola ou 0 nosso Ensino Fundamental) ou ensino secundário (gymnasiet ou o nosso Ensino Médio).

Para além deste curso, existem cursos especializados (Profilkurser) e cursos de formação profissional (Yrkesutbildningar), que preparam os jovens para o ingresso no ensino superior ou fornecem qualificações profissionais para o mercado de trabalho. Essas escolas são mantidas por municípios ou por ONG's (Organizações NãoGovernamentais), cujos e cursos podem ser presenciais (até em regime de internato) ou a distância, e possuem total liberdade de organização curricular e da proposta pedagógica.

Assim, o jovem sueco (e os jovens imigrantes) que conclui o ensino médio, além da opção de frequentar uma escola secundária (folkhögskola), se tiver mais de 18 anos, também tem outras opções para continuar seus estudos. Estas opções são para estudar em uma escola de educação complementar (kompletterande utbildning), em uma educação profissional superior (yrkeshögskolan), em faculdades (högskola) ou nas universidades (universitet).

A educação complementar (kompletterande utbildning) é composta por programas educacionais independentes para jovens e adultos, apoiados pelo poder público, tais como arte, dança, música, teatro, moda, mídia, aviação, saúde etc. Embora existam mais de 300 cursos desse tipo, a maioria deles se concentra na área artística, e muitos deles são uma espécie de faculdade preparatória para o aprofundamento dos estudos nas faculdades, no mesmo campo do conhecimento.

Há também cursos de formação complementar de natureza profissional, como instrutor de voo, cabeleireiro, massagista, etc, para que o jovem, uma vez completado os cursos, possa ingressar no mercado de trabalho. Esses cursos são pós-secundários, ou seja, são cursos superiores (profissionalizantes ou não), mas não são cursos de graduação. Como Folk High Schools (folkhögskola), os cursos de educação complementar (kompletterande utbildning) também permitem que 0 aluno entre em uma faculdade (högskola) ou uma universidade (universitet).

Outra opção que um jovem sueco tem ao terminar a Escola Secundária Superior é o ensino profissional superior (yrkeshögskolan). São também cursos de educação superior voltados mais diretamente ao mercado de trabalho e suas necessidades de mão de obra, de modo que os tipos de cursos oferecidos podem variar de tempos em tempos. Eles são divididos em dois tipos de cursos: cursos de Formação Profissional Superior (HVEC) ${ }^{5} \mathrm{e}$ Qualificação Vocacional $(\mathrm{KY})^{6}$. A principal característica desses cursos é a experiência no local de trabalho, que cobre um terço do curso total.

Tendo completado a Escola Secundária Superior e/ou as Escolas Secundárias Populares (Folk High Schools ou folkhögskola) e/ou a educação

\footnotetext{
${ }^{5}$ Sigla, em inglês, para Higher Vocational Training.

${ }^{6}$ Sigla, em inglês, para Vocationally Qualified.
} 
complementar (kompletterande utbildning), e/ou uma educação profissional superior (yrkeshögskolan), o jovem sueco pode inscrever-se em faculdades (högskola) ou universidades (universitet), sempre respeitando as regras de elegibilidade. Há faculdades (högskola) e universidades (universitet) em mais de 20 cidades em toda a Suécia, com os mais diferentes tipos e programas.

Outra modalidade de educação existente na Suécia que não tem equivalente no sistema educacional brasileiro é o que podemos classificar como educação póssecundária, após o Ensino Médio. Os cursos mais variados oferecidos pelas Folk High Schools (folkhögskola), como os cursos especializados (profilkurser) e cursos de formação profissional (yrkesutbildningar), ou o ensino complementar (kompletterande utbildning), ou 0 ensino profissional superior (yrkeshögskolan), são exemplos suecos do ensino pós-secundário, que podem levar o aluno ao ensino superior (faculdades högskola, ou universidades - universitet) ou ao mercado de trabalho (inserção ou reinserção). No Brasil, por sua vez, o que mais se aproxima de uma educação póssecundária são os chamados cursos sequenciais, que são considerados cursos superiores, mas não cursos de graduação, ou seja, cursos superiores de curta duração.

\section{As opções de ensino médio e Educação Profissional na Espanha}

A educação espanhola é regida pela LOMCE (Ley Orgánica para Mejora de la Calidad Educativa - Ley Orgánica 8/2013, de 9 de dezembro de 2013), denominada popularmente Ley Wert, por conta de ter sido o Ministro da Educação, Cultura e Esporte, José Ignacio Wert, do governo do Primeiro-ministro Mariano Rajoy, que a propôs. Essa lei modifica a Ley Orgánica de Educación no 2 de 3 de maio de 2006 (LOE). Podemos dizer que a LOMCE e a LOE espanhola são, em seu conjunto equivalentes a Skollagen sueca (Lei Educacional de 2010) e a Lei de Diretrizes e Bases da educação brasileira (Lei no 9.394/96).

Os principais objetivos da LOMCE, que reformou a educação espanhola a partir de 2013, são reduzir a taxa de evasão escolar, melhorar os resultados da educação espanhola nas avaliações internacionais (principalmente no $\mathrm{PISA}^{7}$ ), melhorar 0 índice de alunos(as) considerados excelentes (também segundo os parâmetros do PISA), aumentar o número de alunos(as) que terminam com êxito a Educação Secundária obrigatória, melhorar a empregabilidade e estimular o espírito

\footnotetext{
7 PISA - Programa for International Student Assessment (ou, em português, Programa Internacional de Avaliação de Alunos). Trata-se de uma avaliação de larga escala, em nível mundial, de desempenho escolar, realizada pela primeira vez no ano de 2000 e repetida a cada 3 anos, com o objetivo de melhorar as políticas e os resultados educacionais. É coordenado pela Organização para a Cooperação e Desenvolvimento Econômico (OCDE)
} 
empreendedor dos estudantes espanhóis. A obrigatoriedade da educação na Espanha vai até a chamada Educación Secundária Obligatória, no caso, até os 16 anos e é sobre a mesma que vamos trabalhar neste tópico.

A educação básica espanhola é, assim como a Educação Básica brasileira, dividida em três níveis: Educação Infantil (0 a 6 anos), Educação Primária (7 a 12 anos) e Educação Secundária (13 a 16 anos). O conjunto formado pela Educação Primária e pela Educação Secundária espanhola, portanto, excluindo-se a Educação Infantil, é denominado, na Espanha, de Educação Básica ${ }^{8}$.

A partir do ano que a criança completa 6 anos é que se inicia a Educação Básica espanhola propriamente dita. Essa etapa da escolarização na Espanha vai dos 6 aos 16 anos, dividida em dois níveis: a Educação Primária (dos 6 aos 12 anos) e a Educação Secundária (dos 12 aos 16 anos). A Educação Primária compreende 6 cursos (anos) acadêmicos e se organiza em 3 ciclos, cada um com 2 cursos (anos) acadêmicos, chamados de ciclo inicial (6/7 e 8 anos de idade), ciclo médio (9 e 10 anos) e ciclo superior (11 e 12 anos). No interior desses ciclos formativos não existe reprovação e a Educação Primária espanhola é obrigatória e totalmente gratuita.

A segunda etapa da Educação Básica espanhola é a etapa denominada Educación Secundária Obligatoria (ESO). Assim como a Educación Primaria, essa etapa é gratuita e, como a própria denominação coloca, é obrigatória. Geralmente, se inicia no ano que o(a) aluno(a) completa 12 anos e termina aos 16 anos, sendo permitido que o(a) jovem termine essa etapa até os seus 18 anos. É composta por 4 curso (anos) acadêmicos e possui, de forma geral, os mesmos objetivos pedagógicos que a Educación Primaria, claro que com o acréscimo, aprofundamento e diversificação de conteúdos ${ }^{9}$.

Essa etapa, a Educación Secundaria Obligatoria (ESO) espanhola, possui uma especificidade muito importante no contexto do sistema escolar educativo espanhol. Ao fim dela, se aprovado(a), o(a) aluno(a) obtém o título de Graduado(a) em ESO (Educación Secundaria Obligatoria). Com o obtenção desse título (ESO), o(a) aluno(a) pode ingressar no bachillerato ${ }^{10}$, ou em um ciclo formativo de grau médio de formação profissional ${ }^{11}$, ou em um curso de enseñanzas deportivas (desde que seja aprovado também em provas específicas

\footnotetext{
${ }^{8}$ Neste texto, apenas para efeitos de uma melhor explanação didática, quando utilizamos a expressão "Educação Básica" espanhola (com as iniciais em maiúsculo), estaremos nos referindo ao conjunto formado apenas pelos níveis Educação Primária e Educação Secundária espanhola, não incluindo, portanto a Educação Infantil existente na Espanha.

9 A Comunidade Autônoma da Catalunha, por exemplo, alfabetiza em catalão e somente na Educación Secundaria Obligatoria (ESO) é que o(a) aluno(a) vai aprender o idioma Castelhano.

${ }^{10}$ Os cursos de Bachillerato no sistema de educacional espanhol não são equivalentes aos cursos de bacharelado no Brasil.

${ }^{11}$ Para fins de melhorar compreensão do sistema educativo espanhol, vamos considerar, nesse artigo, as seguintes denominações e siglas: FP 0 (Formação Profissional de Nível Básico), FP I (Formação Profissional de Nível Médio) e FP II (Formação Profissional de Nível Superior).
} 
de aptidão física) ${ }^{12}$, ou em cursos de artes plásticas ou desenho. Por outro lado, caso o(a) aluno(a) não consiga ser aprovado(a) ao final da Educación Secundaria Obligatoria (ESO) ele(a) tem as opções que descreveremos abaixo, sempre em função da sua idade.

Se o(a) jovem não aprovado ao final da Educación Secundaria Obligatoria (ESO) possui 16 anos de idade, ele(a) pode ingressar em programas de qualificação profissional inicial (PQPI) ${ }^{13}$, em programas de formação de pessoas adultas ${ }^{14}$, em cursos de ensino de idiomas (a partir dos 14 anos o jovem pode estudar um idioma diferente do idioma cursado na Educación Secundaria Obligatoria) ${ }^{15}$, ou em curso de ensino elementar e profissional de música e dança ${ }^{16}$, desde que, nesse caso, ele também seja aprovado em provas de habilidades específicas.

Porém, se o(a) jovem não aprovado ao final da Educación Secundaria Obligatoria (ESO) já completou 17 anos de idade, ele(a) pode se encaminhar para um ciclo formativo de grau médio ${ }^{17}$, se aprovado em prova de acesso para o mesmo. Por fim, se o(a) jovem não aprovado ao final da Educación Secundaria Obligatoria (ESO) já possui 18 anos, ele(a) pode fazer uma "prova livre" para a obtenção do título de graduado em Educación Secundaria
Obligatoria $(\mathrm{ESO})^{18}$. Somente quando o(a) aluno termina essa etapa (ou a Educación Secundaria Obligatoria ou um ciclo formativo de grau médio) é que o(a) aluno(a) pode ingressar no mundo do trabalho.

A partir do término, com sucesso, da Educación Secundaria Obligatoria (ESO), ou seja, a partir do início do caminho para a Universidade (mas não só para ela, visto que ao fim da Educación Secundaria Obligatoria não se inicia a Universidade, como no Brasil), é que aparecem as maiores diferenças, em termos de percursos e de características, entre 0 sistema educacional espanhol e o brasileiro.

Como já descrevemos alguns parágrafos atrás, ao obter o título da ESO (Educación Secundaria Obligatoria), o(a) jovem pode fazer um curso de Bachillerato nas mais diversas áreas do conhecimento, ou ingressar em um curso de formação profissional de nível médio (FP I), ou ingressar em um curso de enseñanzas deportivas, ou de artes plásticas, ou de desenho. Esses cursos são considerados, no contexto educacional espanhol, como cursos superiores e, além disso, o mercado de trabalho espanhol considera que os jovens egressos desses cursos já

\footnotetext{
12 O curso de enseñanzas deportivas no sistema educativo espanhol seria o equivalente aos cursos de Licenciatura em Educação Física no Brasil, porém, no contexto educacional espanhol eles são o que chamaríamos de "pós-médio" ou, para eles, "pre-grado". São cursos superiores mas não são ministrados nas Universidades.

${ }^{13}$ Essa é a sigla oficial dos programas de Formação Profissional de Nível Básico (que aqui denominamos de FP 0), que é o equivalente, no Brasil, aos cursos profissionalizantes de nível básico.

${ }^{14}$ Cursos de formação inicial de professores para trabalhar com adultos.

${ }^{15}$ Cursos de formação inicial de professores de idiomas.

${ }^{16}$ Cursos de formação inicial de professores de dança e de música.

${ }^{17} \mathrm{O}$ equivalente aos cursos profissionalizantes de nível médio brasileiros.

${ }^{18} \mathrm{O}$ equivalente ao exame supletivo de ensino médio brasileiro.
} 
estão aptos para trabalhar como profissionais de nível superior.

Há que se destacar que os chamados cursos de Bachillerato do sistema educativo espanhol possuem uma forte característica de cursos eminentemente propedêuticos, servindo assim, como uma forma de preparação para a Universidade nas mesmas áreas do curso de Bachillerato realizado. Por outro lado, o mercado de trabalho espanhol, como no caso anterior (cursos de enseñanzas deportivas, cursos de artes plásticas, ou cursos de desenho), também considera que a formação recebida pelo(a) jovem espanhol, caso ele(a) faça a opção por um curso de formação profissional de nível médio (FP I), já é suficiente para que esse(a) jovem ingresse no mercado laboral espanhol, porém, também como no Brasil, a formação profissional de nível médio (FP I) possui menos prestígio social do que a realização do Bachillerato, em qualquer área.

Feita a opção pelos cursos de Bachillerato, ao terminá-lo, com sucesso, o(a) jovem espanhol tem duas opções, caso queira continuar os seus estudos em nível superior. A primeira opção é ingressar na educação superior, em áreas afins ao curso de Bachillerato realizado. A outra opção é encaminhar-se para um curso de formação profissional de nível superior (FP
II). A proporção atual entre essas duas opções é de que $70 \%$ dos(as) jovens espanhóis, quando chegam nesse momento de suas vidas acadêmicas, fazem a opção de ingressar na Universidade. Os outros $30 \%$ fazem a opção de cursar programas de formação profissional de nível superior (FP II).

Para os(as) jovens que não lograram êxito em obter a titulação referente ao término com sucesso da Educación Secundaria Obligatoria (ESO), os(as) jovens denominados "não-titulados", as portas da universidade pública espanhola não estão irremediavelmente fechadas. Ainda existe o caminho, para os(as) jovens de 16 a 24 $\operatorname{anos}^{19}$, de se fazer, inicialmente, um programa de formação profissional de nível básico (FP 0), depois um programa de formação profissional de nível médio (FP I) e, em seguida, um programa de formação profissional de nível superior (FP II). Concluído com sucesso esse último (FP II), o(a) jovem espanhol também está formalmente apto(a) a participar de todo o processo seletivo para ingresso na universidade pública espanhola ${ }^{20}$. Assim, o(a) jovem espanhol pode chegar à Universidade também pelo caminho da formação profissional, primeiramente de nível médio e, em seguida, uma formação profissional de nível superior.

\footnotetext{
${ }^{19}$ A partir dos 25 anos, o(a) jovem/adulto já faz parte do grupo de maiores de 25 anos, portanto passa a ter a opção de ingressar na universidade pública espanhola em função de sua idade.

${ }^{20} \mathrm{Na}$ realidade espanhola, a quantidade de vagas ofertadas pelas universidades públicas é significativamente maior do que a quantidade de vagas oferecidas pelas universidades privadas espanholas, além do fato de que essas últimas (as universidades privadas espanholas) são muito caras no contexto desse país.
} 


\section{Algumas especificidades da Educação Profissional de nível médio no contexto dos sistemas de ensino sueco e espanhol}

$\mathrm{Na}$ Suécia, há tanto os cursos especializados (Profilkurser) quanto os cursos de formação profissional (Yrkesutbildningar), onde ambos preparam os jovens, ou para o ingresso no ensino superior ou para o mercado de trabalho, ao Ihes fornecerem qualificações profissionais, com liberdade de organização curricular e da proposta pedagógica. Além desses cursos, existem ainda os cursos de formação complementar de natureza profissional. Esses cursos são pós-secundários, ou seja, são cursos superiores (profissionalizantes ou não), mas não são cursos de graduação, que poderíamos caracterizar como cursos de nível "pósmédio", que não existem no Brasil, pelo menos não de forma significativa.

Outra diferença que consideramos significativa, existente no contexto educacional sueco, é a existência das Folk High Schools (folkhögskola). Ainda que não se trate especificamente de Educação Profissional de nível médio e que tenham entre os seus objetivos o objetivo de conceder escolaridade primária obrigatória (grundskola ou o nosso Ensino Fundamental) ou ensino secundário (gymnasiet ou o nosso Ensino Médio), portanto, uma espécie de Educação de Jovens e Adultos, a existência de escolas que possuem a missão educar para a defesa da democracia e da luta em defesa dos direitos das minorias, se constitui, em nosso entendimento, um diferencial civilizatório imensurável.

No contexto espanhol, por sua vez, as possibilidades de Educação Profissional de nível médio iniciam-se com o término, com sucesso da Educación Secundaria Obligatoria (ESO), quando o(a) aluno(a) adquire o título de Graduado(a) em ESO (Educación Secundaria Obligatoria) e assim obtém o direito, caso queira, de ingressar em um ciclo formativo de grau médio de formação profissional, ou em alguns cursos específicos que podem ser caracterizados como uma espécie de "pósmédio". um curso de enseñanzas deportivas (desde que seja aprovado também em provas específicas de aptidão física), ou em cursos de artes plásticas ou desenho ${ }^{21}$. O(a) jovem espanhol menor de 17 anos, que foi aprovado na ESO (Educación Secundaria Obligatoria) também pode ingressar em programas de qualificação profissional inicial (PQPI Formação Profissional de Nível Básico), em programas de formação de professores de idiomas, formação de professores de música ou dança ou ainda formação de professores para trabalhar com adultos. Todas essas formações de professores são consideradas, no contexto educacional, como "formação inicial".

Porém, se o(a) jovem não foi aprovado na Educación Secundaria Obligatoria (ESO) e

${ }^{21}$ Como já citamos os exemplos dos cursos de enseñanzas deportivas, artes plásticas ou desenho. 
já completou 17 anos de idade, sua opção é se encaminhar para um ciclo formativo de grau médio, que são equivalentes aos cursos profissionalizantes de nível médio brasileiros, se aprovado em prova de acesso para o mesmo. Por fim, se o(a) jovem não aprovado ao final da Educación Secundaria Obligatoria (ESO) mas já possui 18 anos, ele(a) pode fazer uma "prova livre" para a obtenção do título de graduado em Educación Secundaria Obligatoria (ESO), que é o equivalente ao exame supletivo de ensino médio brasileiro, ou seja, sem o grau escolar conferido pela Educación Secundaria Obligatoria, o(a) jovem espanhol não ingressa no mundo do trabalho com uma formação profissionalizante de nível médio.

\section{Considerações finais}

Em momento algum de nossa pesquisa tivemos a intenção poder chegar ao final da mesma em condições de fazermos qualquer assertiva no sentido de que a Educação Profissional de nível médio ofertada na Suécia ou na Espanha são de melhor qualidade do que a Educação Profissional de nível médio existente no Brasil. Nosso objetivo foi o de mostrar os itinerários formativos dessa modalidade de ensino de nível médio, nesses dois países europeus.

Qualquer assertiva dessa natureza seria leviana dado o fato de que não foi esse o objetivo do presente artigo. Além disso, uma das premissas básicas do campo metodológico onde se inserem os estudos comparativos, indica que cada sistema e, portanto, cada nível ou modalidade de ensino que o compõe, possui as suas peculiaridades e especificidades que, por sua vez, estão assentadas na história, na cultura, nos costumes e nas tradições de cada uma de suas respectivas sociedades, no contexto das quais se estabelecem a organização, estruturação, normatizações, currículos e conteúdos existentes nos próprios sistemas de ensino.

No campo teórico e metodológico da Educação Comparada, Makuwira \& Ninnes (2004) argumentam que uma das principais questões desse campo refere-se ao papel da Educação Comparada para o desenvolvimento das comunidades locais, evitando-se, à todo custo, substituir a agenda local (a resolução de problemas locais) por uma agenda global e transnacional, que desconsidera as realidades locais. De fato, como Halls (1990) disse, estudamos a educação estrangeira, com os estudos comparativos em métodos educacionais, porque, entre outras coisas, queremos melhorar nosso próprio sistema educacional.

Nesse sentido, apontar os caminhos existentes em países desenvolvidos em contraposição aos caminhos existentes na nossa realidade educacional nos permite, principalmente, identificar as diferenças sem, necessariamente, adjetivá-las como "melhores que" ou "piores que". Assim, podemos afirmar que há diferenças significativas entre as possibilidades de 
itinerários formativos pela via da Educação Profissional de nível médio da Suécia e da Espanha em comparação com a realidade educacional brasileira na mesma modalidade de ensino, contrariando a ideia de Ragin (1987) sobre as chamadas "diferenças ilusórias". As diferenças que encontramos em nossa análise não possuem características que nos permitam chamar essas diferenças de "ilusórias", muito pelo contrário, essas diferenças são significativas, importantes e reais, muito reais.

A principal diferença que encontramos foi, tanto no contexto sueco como no contexto espanhol, existe a possibilidade de que o(a) jovem trilhe diferentes percursos formativos no campo da Educação Profissional de nível médio (e, por vezes, até na Educação Profissional oferecida em nível superior), sem que esse percurso "feche as portas" da Universidade para ele(a), ao passo que na realidade educacional brasileira, no mais das vezes, a opção pelo caminho da Educação Profissional de nível médio coloca-se em oposição e, portanto, em exclusão) ao caminho rumo à educação superior em nossas faculdades, centros universitários e universidades.
Um sentimento presente nas três sociedades, ainda que em graus diferentes, é o antigo preconceito com a Educação Profissional, especialmente a oferecida em nível médio, em relação à formação adquirida na Educação Superior. O que pudemos notar é que, quanto maior a quantidade de possibilidades de itinerários educacionais que levem à Educação Superior, itinerários estes que passam também pela Educação Profissional de nível médio, menor é o referido preconceito.

Consideramos também que o problema do menor prestígio social que a Educação Profissional de nível médio goza, também em países desenvolvidos como Suécia e Espanha, quando comparado com a formação de nível superior oferecida pela Universidade, não se constitui em um problema específico de uma ou outra sociedade, mas sim, um problema inerente às sociedades capitalistas, onde o "trabalho manual" é sempre menos valorizado que o "trabalho intelectual".

Recebido em 12 de novembro de 2020. Aprovado em 23 de junho de 2021. 
Bray, M., Adamson, B. \& Mason, M. (2015). Modelos diferentes, ênfases diferentes, discernimentos diferentes. In: Bray, M., Adamson, B. \& Mason, M. (Orgs.). Pesquisa em educação comparada: abordagens e métodos (pp. 457-476). Brasília: Liber Livro.

Broadfoot, P. (2000). Comparative Education for the $21^{\text {st }}$ century: retrospect and prospect. Comparative Education, 36 (3), 357-371. https://doi.org/10.1080/03050060050129036.

Broadfoot, P. (2012). Tempos de revolução científica? Da educação comparada à ciência comparada de aprendizagem. In: Cowen, R., Kazamias, A. \& Unterhalter, E. (Orgs.). Educação comparada: panorama internacional e perspectivas (pp. 717-738). Brasília: UNESCO/CAPES, (2).

Carvalho, E. J. G. (2014). Estudos Comparados em Educação: novos enfoques teórico$\begin{array}{lllll}\text { metodológicos. } & \text { Acta } & \text { Scientiarum, } & 36 & \text { (1), }\end{array}$ https://doi.org/10.4025/actascieduc.v36i1.19012.

Cook, B., Hite, S. \& Epstein, E. (1998). Discerning Trends, Contours and Boundaries in Comparative Education: survey of comparativists and their literature. Comparative Education Review, (48), 123-149. Recuperado de https://www.journals.uchicago.edu/doi/10.1086/382619. Acesso em 06 jan. 2021.

Cowen, R. (2000). Comparing Futures or Comparing Pasts? Comparative Education, (36), 333-342.

Franco, M. A. C. (1992). Estudos Comparados em Educação na América Latina: uma discussão teórico-metodológica a partir da questão do outro. In: Puiggrós, A., Bertussi, G. T. \& Franco, M. A. C. (Orgs.). Estudos Comparados e Educação na América Latina. São Paulo: Livros do Tatu/Cortez.

Halls, W. D. (1990). Trends and Issues in Comparative Education. In: Halls, W. D. (Org.). Comparative Education: contemporary issues and trends. London: Jessica Kingsley Publishers.

Kaloyannaki, P. \& Kazamias, A. (2012). Os primórdios modernistas da educação comparada: o tema protocientífico e administrativo reformista-meliorista. In: Cowen, R., Kazamias, A. \& Unterhalter, E. (Orgs.). Educação comparada: panorama internacional e perspectivas. (pp. 25-80). Brasília: UNESCO/CAPES, (1).

Kandel, I. L. (1933). Studies in Comparative Education. Boston: Houghton Mifflin Company.

King, E. (1965). The Purpose of Comparative Education. Comparative Education, 3 (1), 147-159. https://doi.org/10.1080/0305006650010302.

Lima, L. C. V. S. \& Afonso, A. J. G. (2002). Democratização, modernização e neoliberalismo. Porto: Edições Afrontamento.

Lourenço Filho, M. B. (2004). Educação Comparada. 3. ed. Brasília: MEC/Inep. 
Makuwira, J. \& Ninnes, P. (2004). Post-Development Theory and Comparative Education. In: Ninnes, P. \& Mehta, S. (Orgs.). Re-Imagining Comparative Education: postfoundational ideas and applications for critical times. New York; London: RoutledgeFalmer.

Phillips, D. \& Ochs, K. (2003). Processes of Policy Borrowing in Education: some explanatory and analytical devices. Comparative Education, 39 (4), 451-461. https://doi.org/10.1080/0305006032000162020

Ragin, C. (1987). The Comparative Method: moving beyond qualitative and quantitative strategies. Berkeley: University of California Press.

Sadler, M. (1900). How can we learn anything of practical value from the study of foreign systems of education? Comparative Education Review, 7 (3), 307-314 [Reimpresso em 1964].

Steiner-Khamsi, G. (2004). The Global Politics of Educational Borrowing and Lending. New York: Teachers College Press.

Wikander, L. (2010). The Educational System in Sweden: from a uniform towards a dual model. Pedagogisk Forskning I Uppsala, 158, 5-42. 